Старцев Сергей Викторович, $\partial-p$ техн. наук, проф. кафедры «Техническое обеспечение АПК», Саратовский государственный аграрный университет имени Н.И. Вавилова. Россия.

Агеев Алексей Владимирович, аспирант кафедры «Техническое обеспечение АПК», Саратовс- кий государственный аграрный университет имени Н.И. Вавилова. Россия

410056, г. Саратов, ул. Советская, 60.

Тел.: (8452) 74-96-53.

Ключевые слова: пахотный агрегат; конструкиця; трактор; плуг.

\title{
THE RESULTS OF EXPERIMENTAL STUDIES OF ARABLE UNIT MTZ-82+PBS-3M
}

Boykov Vasiliy Mihaylovich, Doctor of Technical Sciences, Professor of the chair "Technical Equipment of AIC", Saratov State Agrarian University named after N.I. Vavilov. Russia.

Startsev Sergey Viktorovich, Doctor of Technical Sciences, Professor of the chair "Technical Equipment of AIC", Saratov State Agrarian University named after N.I. Vavilov. Russia.

Ageev Aleksey Vladimirovich, Post-graduate Student of the chair "Technical Equipment of AIC", Saratov State Agrarian University named after N.I. Vavilov. Russia.

Keywords: arable unit; construction; tractor; plough.
It is given the description of the design and specifications developed in Saratov State Agrarian University plow-blade grader of general purpose $P B S-3 M$ aggregated with tractors of traction class 1.4. In the result of experimental researches of the arable unit consisting of the MTZ-82 tractor and the plow PBS-3M on a stubble background of the field with soil of low humidity and high hardness operational and technological indicators of the unit on the main dump processing of the soil are defined. Studies were conducted in three ways: plough PBS-3M fitted with three frames, fitted with two frames, with removed front frame; fitted with two frames, removed the rear frame. The graphical dependences of the plow traction resistance and the unit performance on the speed of MTZ-82+PBS-3M are presented.

удк 631.3.004.67

\section{РАСЧЕТНАЯ ОЦЕНКА ПРИМЕНЕНИЯ РАСПЛАВОВ ЭЛЕКТРОЛИТА ПРИ УПРОЧНЕНИИ ВОССТАНОВЛЕННЫХ РАБОЧИХ ОРГАНОВ ПОЧВООБРАБАТЫВАЮЩИХ И ПОСЕВНЫХ АГРЕГАТОВ}

БУйлов Валерий Николаевич, Саратовский государственный аграрный университет имени Н.И. Вавилова

Обоснована необходимость разработки математической модели расчетно-теоретической проверки применимости различных составов электролита для борирования. Предложены формулы и системы уравнений, представляющие собой такую математическую модель. Результаты расчетов по этим формулам позволили оценить несколько составов электролита и установить предпочтительный вариант для борирования при упрочнении восстановленных рабочих органов почвообрабатывающих и посевных агрегатов.

Введение. При принятии технологических решений необходимо провести их теоретическое обоснование [11]. Поэтому требуется математическое моделирование основных технологических операций упрочнения дополнительной детали при восстановлении работоспособности рабочих органов почвообрабатывающих и посевных агрегатов с повышением их ресурса. В результате научных и технологических исследований был разработан способ электролизного борирования этих деталей.

Математическое моделирование движения ионов в расплаве электролита требует учета процессов конвекции, миграции и диффузии. Действующая на ион сила электрического поля заставляет его двигаться с определенной скоростью, которая определяется его подвижностью. Диффузия ионов выражается через градиент концентрации $[1,2]$.

Методика исследований. Перемещение ионов, обеспечивающееся движением расплавленной среды, является его конвективной составляющей. Поэтому поток $i$-х ионов, перемещающихся в движущейся расплавленной среде $[1,10]$, описывается системой $(1)$ :

$$
J_{i}=C \bar{V}-D_{i} g r a d C_{i}+\frac{C_{i} D_{i} Z_{z}^{i} F E_{\text {эп }}}{R_{y} T},
$$

где $C_{i}-$ концентрация $i$-го иона, моль/л; $\bar{V}-$ поле скоростей течения расплавленной сплошной среды, м/с; $D_{i}-$ коэффициент диффузии $i$-го иона, $\mathrm{M}^{2} / \mathrm{c} ; Z_{i}^{z}$ - заряд $i$-го иона; $F$ - постоянная Фарадея, Кл/моль; $\mathrm{E}_{\text {эп }}$ - напряженность элект- 
рического поля в расплаве, B; $T$ - температура процесса, ${ }^{\circ} \mathrm{C} ; R_{y}-$ универсальная газовая постоянная, Дж/К·моль.

Результаты исследований. Исходя из закона сохранения вещества, учитывая несжимаемость жидкости, постоянство ее температуры и коэффициента диффузии, получаем систему уравнений (2), описывающую направленное движение ионов в жидкой среде $[1,7,10]$ :

$$
\frac{\partial C_{i}}{\partial t}=(\bar{V} g r a d) C_{i}=D_{i} \Delta C_{i}+\frac{D_{i} Z_{i}^{z} F}{R_{y} T}+\operatorname{div}\left(C_{i} \mathrm{E}_{\text {эп }}\right),
$$

где $t$ - время прохождения процесса, с.

Изменение концентраций ионов в расплаве меняет величину напряженности электрического поля в нем. Следовательно, для решения этой системы учитывается плотность заряда в расплаве электролита (3).

$$
\sum_{i=1}^{n} Z_{i}^{z} C_{i}=0
$$

Исходя из условия, что на катоде разряжаются катионы бора, а на аноде анионы кислорода, то расплав электролита бинарный. В таком случае математическая модель этих процессов [2-7] строится следующим образом:

$$
\begin{aligned}
& \frac{\partial C_{2}}{\partial t}+(\bar{V} \text { grad }) C_{2}=D_{2} \Delta C_{2}+\frac{D_{2} Z_{2}^{z} F}{R_{y} T} \operatorname{div}\left(C_{2} \mathrm{E}_{\text {эп }}\right), \\
& \frac{\partial C_{3}}{\partial t}+(\bar{V} \text { grad }) C_{3}=D_{3} \Delta C_{3}-\frac{D_{3} Z_{3}^{z} F}{R_{y} T} \operatorname{div}\left(C_{3} \mathrm{E}_{\text {эп }}\right),
\end{aligned}
$$

где $C_{3}$ - концентрация аниона кислорода в электролите, моль/л; $Z_{3}^{z}$ - заряд аниона кислорода; $D_{3}-$ коэффициент диффузии аниона кислорода в электролите, $\mathrm{M}^{2} / \mathrm{c}$.

Исходя из условия электронейтральности, заменим концентрации катионов и анионов обобщенной молярной концентрацией ионов (6).

$$
C_{M}^{0}=\frac{C_{2}}{Z_{2}^{z}}=\frac{C_{3}}{Z_{3}^{z}} .
$$

Получаем системы (7) и (8).

$$
\begin{aligned}
& \frac{\partial C_{\mathrm{M}}^{0}}{\partial t}+(\operatorname{Vgrad}) C_{\mathrm{M}}^{0}=D_{2} \Delta C_{M}^{0}+ \\
& +\mid \frac{D_{2} Z_{2}^{z} F}{R_{y} T} \operatorname{div}\left(C^{0}{ }_{M} \mathrm{E}_{\text {эп }}\right), \\
& \frac{\partial C_{\mathrm{M}}^{0}}{\partial t}+(\operatorname{Vgrad}) C_{\mathrm{M}}^{0}=D_{3} \Delta C_{M}^{0}+ \\
& +\mid \frac{D_{3} Z_{3}^{z} F}{R_{y} T} \operatorname{div}\left(C^{0}{ }_{M} \mathrm{E}_{\text {эп }}\right) .
\end{aligned} .
$$

После алгебраических преобразований получаем следующее выражение:

$$
\left(D_{3}-D_{2}\right) R_{y} T \Delta C_{M}^{0}=\left(Z_{2}^{z}+Z_{3}^{z} D_{3}\right) F \operatorname{div}\left(C_{M}^{0} \mathrm{E}_{\text {эп }}\right) \text {. }
$$

Применим выражение для расчета эффективного коэффициента диффузии (10).

$$
D_{\ni}=\frac{D_{2} D_{3}\left(Z_{2}^{z}+Z_{3}^{z}\right)}{D_{2} Z_{2}^{z}+D_{3} Z_{3}^{z}} .
$$

На граничной поверхности стоки ионов не оказывают влияния на диффузию, так как описывается баланс ионов в объема расплава [2-7]. Поэтому конвективная диффузия при электролизе стационарный процесс.

После преобразований получаем систему, описывающую перенос ионов в расплаве электролита диффузией и конвекцией:

$$
(\overline{\operatorname{Vgrad}}) C_{M}^{0}=D_{\ni} \Delta C_{M}^{0} .
$$

Диффузионный перенос катионов бора в расплаве электролита количественно оценивается с учетом числа Прандтля [2-7] по следующей формуле:

$$
\sigma=\frac{v^{p}}{D_{2}}=\frac{v^{p}}{k^{p}}
$$

где $v^{p}$ - кинематическая вязкость расплава, $\mathrm{M}^{2} / \mathrm{c}$; $k^{p}$ - температуропроводность расплава, $\mathrm{M}^{2} / \mathrm{c}$.

Кинематическая вязкость расплава определяется следующей формулой:

$$
v^{p}=\frac{\eta_{\text {дв }}^{p}}{\rho_{s t m}},
$$

где $\eta_{д в}^{p}$ - динамическая вязкость расплава, н·с $/ \mathrm{M}^{2}$.

Коэффициент диффузии ионов бора в объеме расплава [2-7] определяется следующим уравнением:

$$
D_{2}=\frac{k_{b} T}{6 \pi \eta_{\text {дв }}^{p} \mathrm{r}_{\sigma}^{u}},
$$

где $r_{\sigma}^{u}$ - радиус катиона бора, м.

Коэффициент диффузии анионов кислорода в объеме расплава определяется аналогичным уравнением:

$$
D_{3}=\frac{k_{b} T}{6 \pi \eta_{\text {дв }}^{p} r_{k}^{u}},
$$

где $r_{\kappa}^{u}$ - радиус иона кислорода, м. 
Число Прандтля для этого расплава превышает миллион, а коэффициент диффузии очень мал, поэтому даже при незначительной конвекции ионы в объеме транспортируются конвективными потоками, таким образом, диффузионной составляющей пренебрегаем $[1,10]$. В результате получаем систему, описывающую конвективный перенос ионов в расплаве электролита (16).

$$
(\bar{V} \operatorname{grad}) C_{i}=0
$$

Решения этой системы справедливы в поверхностной зоне пограничного слоя Прандтля, где имеют место и конвективный и диффузионный перенос ионов. Он происходит и по нормали к этому слою и параллельно ему $[1,10]$. По длине омываемой поверхности катода из-за влияния тангенциальной составляющей конвекции толщина пограничного слоя меняется(17).

$$
\delta_{\Pi р}=5,2 w-0,5\left(v^{p} z\right)^{0,5},
$$

где $\delta_{\text {Пр }}$ - толщина слоя Прандтля, м; $w$ - величина скорости движения расплава вдоль катода, м/с; $z$ - координата по оси направленной вдоль поверхности катода, м.

В диффузионной зоне пограничного слоя конвективная составляющая транспортирования ионов снижается практически до нуля, а диффузионная составляющая становится преобладающей, несмотря на малый коэффициент диффузии. Толщина этого слоя составляет десятую часть пограничного слоя $[1,10]$ и находится непосредственно на катоде (18).

$$
\delta_{\partial}=5,2\left(v^{p}\right)^{017} z^{0,5} w^{-0,5} D_{2}^{0,33} .
$$

Поверхность катода равнодоступна для прохождения процесса электролиза ионов и полубесконечна, так как радиус кривизны этой поверхности и ее линейные размеры на несколько порядков превышают толщину пограничного слоя [2-7].

Учитывая следующие условия $\partial^{2} C_{2} / \partial y^{2} \gg \partial^{2} C_{2} / \partial z^{2}, w>>(u-$ величина скорости движения расплава ортогонально катоду, м/c), а $\partial C_{2} / \partial y \gg \partial C_{2} / \partial z$ диффузионный поток катионов бора в пограничном слое определяется следующим выражением:

$$
\begin{gathered}
J_{2}^{D}=D_{2}\left(\frac{\partial C_{2}}{\partial y}\right)_{y=0}= \\
=0,34 C_{2}^{0} w^{0,5}\left(v^{p} z\right)^{-0,5}\left(D_{2}^{2} v^{p}\right)^{0,33} .
\end{gathered}
$$

Суммарный поток ионов в пограничном слое определяется выражением (20).

$$
\begin{aligned}
J_{2}^{D, K}=D_{2} & \left(\frac{\partial \mathrm{C}_{2}}{\partial y}\right)_{y=0}=0,68 C_{2}^{0} b_{k}\left(w l_{k}\right)^{0,5} \times \\
& \times\left(v^{p} z\right)^{-0,5}\left(D_{2}^{2} v^{p}\right)^{0,33},
\end{aligned}
$$

где $l_{k}, b_{k}$ - длина и ширина поверхности катода, м.

Ионы, достигающие поверхности катода, практически мгновенно разряжаются, поэтому их концентрация в прикатодном слое расплава электролита уменьшается до очень малой величины, что свидетельствует о максимальной разности концентраций ионов в расплаве и прикатодном слое, а это увеличивает их поток.

Повышение плотности катодного тока и его потенциала не компенсирует падение концентрации катионов бора, то доставка недостающего их количества обеспечивается диффузией. Таким образом, кинетика этого процесса в пограничном слое определяется их диффузией [2-7].

Молярная концентрация ионов не зависит от электрического поля, наведенного в электролите. Напряженность этого поля, учитывая разнонаправленное движение катионов и анионов (уравновешивающего ток в расплаве бинарного электролита), определяется следующей системой:

$$
\mathrm{E}_{\text {эп }}=\frac{R_{y} T\left(D_{2}-D_{3}\right)}{F\left(Z_{2}^{z} D_{2}+Z_{3}^{z} D_{3}\right)} \frac{\operatorname{grad} C_{M}^{0}}{C_{M}^{0}} .
$$

Так как количество ионов, перемещающихся к поверхности электрода, равняется количеству ионов, восстанавливающихся на этой поверхности (стационарный режим электролиза), то для определения диффузионного потенциала бинарного электролита (22) применимо уравнение Нернста.

$$
\varphi_{D}=\varphi_{D}^{0}+\frac{R_{y} T\left(D_{2}-D_{3}\right)}{F\left(Z_{2}^{z} D_{2}+Z_{3}^{z} D_{3}\right)} \ln C_{M}^{0},
$$

где $\varphi_{D}^{0}$ - потенциал электрода без концентрационной поляризации, В.

Плотность катодного тока определяется по следующему соотношению:

$$
i_{k}=\frac{Z_{2}^{z} F D_{2}}{\left(1-n_{k b}\right) \delta_{\partial}}\left(C_{2}^{0}-C_{2}^{k}\right)
$$

где $C_{2}^{k}$ - концентрация ионов бора у поверхности катода, моль $/ \mathrm{m}^{3} ; n_{k b}$ - число переноса ионов бора.

Уменьшение концентрации ионов бора в прикатодном слое практически до нуля приводит к тому, что катодная плотность тока принимает максимальное значение (24).

$$
i_{k n}=\frac{Z_{2}^{z} F D_{2}}{\left(1-n_{k b}\right) \delta_{\partial}} C_{2}^{0} .
$$


Концентрация ионов бора у поверхности катода определяется по выражению (25).

$$
C_{2}^{k}=C_{2}^{0}\left(i_{k n}-i_{k}\right) \cdot\left(i_{k n}\right)^{-1} \text {. }
$$

Результаты расчетов по приведенным формулам (1)-(25) сведены в табл. 1-3.

Заключение. Сравнительная расчетная оценка возможности использования существующих и предлагаемого электролитов для упрочнения восстановленных рабочих органов почвообрабатывающих и посевных агрегатов позволяет утверждать, что применение нового состава [8] обеспечивает на $10 \%$ больший диффузионный поток и на 25 \% большую концентрацию катионов в прикатодном слое, чем существующие составы. Это способствует повышению толщины упрочненного слоя, что в свою очередь ведет к увеличению ресурса восстановленных рабочих органов почвообрабатывающих и посевных агрегатов.

\section{СПИСОК ЛИТЕРАТУРЫ}

1. Барабошкин А.Н. Электрокристаллизация металлов из расплавленных солей. - М.: Наука, 1976. - 223 с.

2. Буйлов В.Н., Люляков И.В. Диффузионная кине- тика процесса электролизного борирования // Материалы Междунар. науч.-практ. конф. - Саратов, 2005. C. 36-39.

3. Буйлов В.Н., Люляков И.В. Диффузионная кинетика процесса упрочнения рабочих органов культиваторов // Защитные покрытия в машиностроении и приборостроении: материалы 2-й Всерос. науч.-практ. конф. - Пенза, 2005. - С. 39-42.

4. Буйлов В.Н., Люляков И.В. Теоретические основы кинетики диффузионных процессов при электролизном борировании // Проблемы экономичности и эксплуатации двигателей внутреннего сгорания в АПК: материалы Межгос. науч.-техн. семинара. - Саратов, 2006. - С. 44-46.

5. Буйлов В.Н., Пронин С.А. Математическое моделирование тепломассообменных процессов при обработке деталей в электродной печи-ванне // Вестник Саратовского госагроуниверситета им. Н.И. Вавилова. - 2011. - № 7. - С. 46-49.

6. Джашитов В.Э., Панкратов В.М., Голиков А.В. Математическая модель динамических тепломассообменных процессов в стекловаренной печи // ИФЖ. 2003. - Т. 76. - № 5. - С. 117-124.

7. Криштал М.А., Волков А.И. Многокомпонентная диффузия в металлах. - М., 1985. - 176 с.

Таблица 1

\section{Суммарный диффузионный поток ионов бора}

\begin{tabular}{|c|c|c|c|}
\hline \multirow{2}{*}{$\begin{array}{c}\text { Скорость конвективного } \\
\text { движения расплава, м/с }\end{array}$} & \multicolumn{3}{|c|}{ Диффузионный поток катионов бора в расплавах теплоносителя, $\times 10^{-5}$ моль $/ \mathrm{M}^{2} \mathrm{c}$} \\
\cline { 2 - 4 } & $\begin{array}{c}80 \% \text { буры }+20 \% \\
\text { фтористого натрия [9] }\end{array}$ & $100 \%$ буры [9] & Предлагаемый состав [8] \\
\hline 0,01 & 2,54 & 3,55 & 3,95 \\
\hline 0,05 & 5,68 & 7,94 & 8,83 \\
\hline 0,10 & 8,03 & 11,23 & 12,5 \\
\hline 0,15 & 9,84 & 13,75 & 15,3 \\
\hline 0,20 & 11,36 & 15,88 & 17,7 \\
\hline 0,26 & 12,95 & 18,1 & 20,1 \\
\hline
\end{tabular}

Таблица 2

Максимальные значения катодной плотности тока

\begin{tabular}{|c|c|c|c|c|c|c|c|c|c|}
\hline \multirow[b]{3}{*}{ 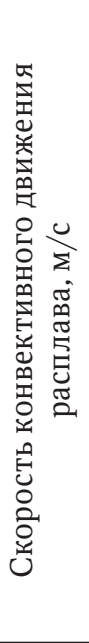 } & \multicolumn{9}{|c|}{$\begin{array}{c}\text { Состав расплава теплоносителя (электролита) и параметры технологического } \\
\text { процесса электролизного борирования }\end{array}$} \\
\hline & \multicolumn{3}{|c|}{$\begin{array}{c}80 \% \text { буры }+20 \% \text { фтористого } \\
\text { натрия [9] } \\
\end{array}$} & \multicolumn{3}{|c|}{100 \% буры [9] } & \multicolumn{3}{|c|}{ Предлагаемый состав [8] } \\
\hline & 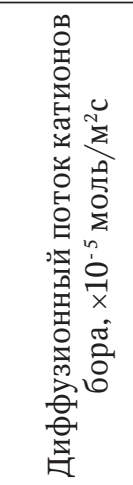 & 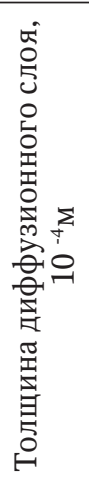 & 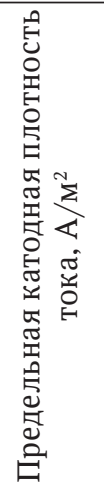 & 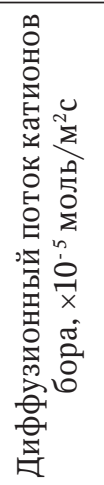 & 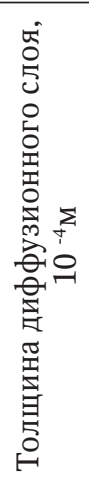 & 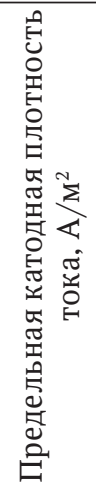 & 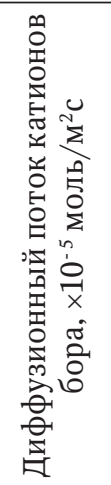 & 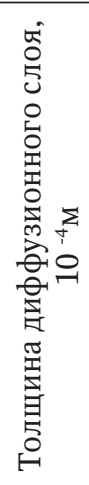 & 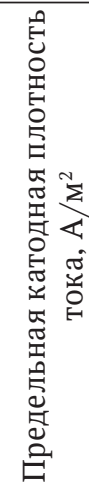 \\
\hline 0,01 & 2,54 & 14,2 & 377,5 & 3,55 & 13,5 & 574,8 & 3,95 & 13,7 & 634,3 \\
\hline 0,05 & 5,68 & 6,3 & 850,8 & 7,94 & 6,0 & 1293 & 8,83 & 6,1 & 1424 \\
\hline 0,10 & 8,03 & 4,5 & 1191 & 11,23 & 4,2 & 1847 & 12,5 & 4,3 & 2021 \\
\hline 0,15 & 9,84 & 3,7 & 1448 & 13,75 & 3,5 & 2217 & 15,3 & 3,5 & 2483 \\
\hline 0,20 & 11,36 & 3,2 & 1675 & 15,88 & 3,0 & 2586 & 17,7 & 3,1 & 2803 \\
\hline & 12,95 & 2,78 & 1928 & 18,1 & 2,65 & 8 & 20,1 & 2,69 & 3230 \\
\hline
\end{tabular}


Концентрации ионов бора в прикатодном слое

\begin{tabular}{|c|c|c|c|c|c|c|c|c|}
\hline \multicolumn{3}{|c|}{80 \% буры + 20 \% фтористого натрия [9] } & \multicolumn{3}{|c|}{100 \% буры [9] } & \multicolumn{3}{|c|}{ Предлагаемый состав [8] } \\
\hline 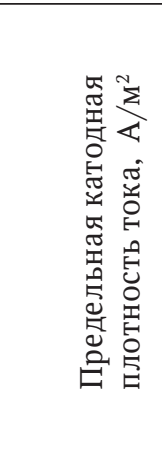 & 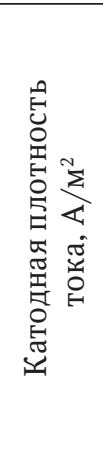 & 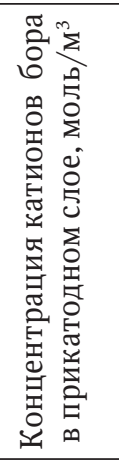 & 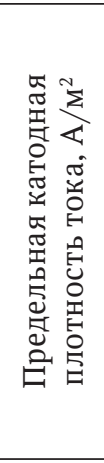 & 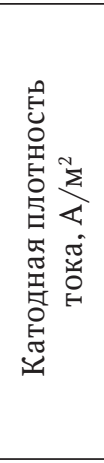 & 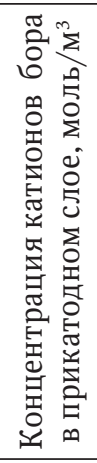 & 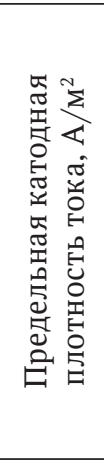 & 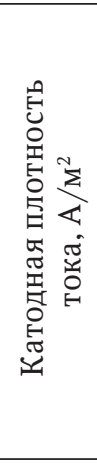 & 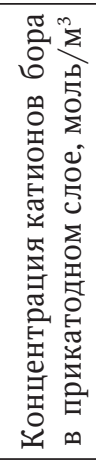 \\
\hline 1191 & 1500 & - & 1847 & 1500 & 2500 & 2021 & 1500 & 3815 \\
\hline 1448 & 1500 & - & 2217 & 1500 & 4300 & 2483 & 1500 & 5860 \\
\hline 1675 & 1500 & 992 & 2586 & 1500 & 5585 & 2803 & 1500 & 6880 \\
\hline 1928 & 1500 & 2109 & 2928 & 1500 & 6486 & 3230 & 1500 & 7930 \\
\hline 377 & 1750 & - & 575 & 1750 & - & 634 & 1750 & - \\
\hline 850 & 1750 & - & 1293 & 1750 & - & 1424 & 1750 & - \\
\hline 1191 & 1750 & - & 1847 & 1750 & 700 & 2021 & 1750 & 1985 \\
\hline 1448 & 1750 & - & 2217 & 1750 & 2800 & 2483 & 1750 & 4370 \\
\hline 1675 & 1750 & - & 2586 & 1750 & 4300 & 2803 & 1750 & 5560 \\
\hline 1928 & 1750 & 878 & 2928 & 1750 & 5350 & 3230 & 1750 & 6780 \\
\hline 377 & 2000 & - & 575 & 2000 & - & 634 & 2000 & _. \\
\hline 850 & 2000 & - & 1293 & 2000 & - & 1424 & 2000 & - \\
\hline 1191 & 2000 & - & 1847 & 2000 & - & 2021 & 2000 & 154 \\
\hline 1448 & 2000 & - & 2217 & 2000 & 1300 & 2483 & 2000 & 2880 \\
\hline 1675 & 2000 & - & 2586 & 2000 & 3014 & 2803 & 2000 & 4240 \\
\hline 1928 & 2000 & - & 2928 & 2000 & 4215 & 3230 & 2000 & 5636 \\
\hline
\end{tabular}


8. Патент 2114184 Российская Федерация, МКП ${ }^{6} \mathrm{C}$ 21 D1/34, В 23 К 35/362. Шлак для нагрева и наплавки металлов и сплавов / В.Н. Буйлов, Б.П. Загородских, В.П. Синичкин, В.К. Петряков, В.В. Сафонов, С.А. Богатырев, А.Л. Нестеров; заявл. 12.09.97; опубл. 27.06.98, Бюл. № 18.

9. Полевой С.Н., Евдокимов В.Д. Упрочнение металлов. - М.: Машиностроение, 1986. - 319 с.

10. Чеботин В.Н., Перфильев М.В. Электрохимия твердых электролитов. - М.: Химия, 1978. - 315 с.

11. Рудик Ф.Я., Богатырев С.А. Анализ условий работы и износного состояния ножей центробежных свеклорезок // Аграрный научный журнал. - 2018. № 3. - C. 47-50.

Буйлов Валерий Николаевич, канд. техн. наук, доцент кафедры «Техническое обеспечение АПК», Сaратовский государственный аграрный университет имени Н.И. Вавилова. Россия.

410056, г. Саратов, ул. Советская, 60.

Тел.: (8452) 74-96-29.

Ключевые слова: рабочий орган; расплав электролита; диффузия; катион; ион; математическое моделирование.

\section{SETTLEMENT ESTIMATION OF ELECTROLYTE MELTS APPLICATION FOR STRENGTHENING RECOVERED WORKING BODIES OF TILLAGE AND SOWING UNITS}

Builov Valeriy Nikolaevich, Candidate of Technical Sciences, Associate Professor of the chair "Technical Support of AIC", Saratov State Agrarian University named after N.I. Vailov. Russia.

Keywords: working body; electrolyte melt; diffusion; cation; ion; math modeling.

The necessity of developing a math model of theoretical calculation of the applicability of various electrolyte compositions for boration is substantiated. Formulas and systems of equations that represent such a math model are proposed. The results of calculations based on these formulas made it possible to evaluate several electrolyte compositions and to establish the preferred option for boration in strengthening the restored working bodies of tillage and sowing units.

УдК 631.311 .86

\section{ИССЛЕДОВАНИЕ ВЛИЯНИЯ КОНСТРУКТИВНЫХ И РЕЖИМНЫХ ПАРАМЕТРОВ КОМБИНИРОВАННОГО УКЛАДЧИКА НА МОЩНОСТЬ ПРИВОДА РАБОЧИХ ОРГАНОВ}

ПАВЛОВ Павел Иванович, Саратовский государственный аграрный университет имени Н.И. Вавилова

КОРСАК Виктор Владиславович, Саратовский государственный аграрный университет имени Н.И. Вавилова

ВЕЗИРОВ Александр Олегович, Саратовский государственный аграрный университет имени Н.И. Вавилова

МУХИН Дмитрий Вадимович, Саратовский государственный аграрный университет имени Н.И. Вавилова

Получены уравнения регрессии и графические зависимости, описывающие влияние конструктивных и режимных параметров на мощность привода рабочих органов. Экспериментальным путем определено значение конструктивных и режимных параметров, при которых мощность, необходимая для привода рабочих органов, будет иметь минимальное значение.

Введение. Применение почвенных смесей, образованных из естественных компонентов, составляет основу для распространенных технологий производства овощей в тепличном производстве, что дает возможность получать овощную продукцию с улучшенными товарновкусовыми качествами. Преимущество таких почвенных смесей - их высокая однородность по показателям кислотности и содержанию питательных веществ, что необходимо для роста и развития растений [4]. Процесс приготовления включает в себя несколько последовательных технологических операций: послойную укладку почвенных компонентов, смешивание, загрузку в транспортное средство, транспортирование, укладку почвы на поверхность теплицы [2]. Процесс послойной укладки почвенных компонен- тов является наиболее трудоемким, поскольку существующие технологии позволяют производить укладку одного компонента за один проход машины, часто для качественного выполнения данного процесса необходим ручной труд. Предложенная конструкция комбинированного укладчика позволяет решить эту задачу и проводить с заданной производительностью укладку до трех компонентов одновременно [7].

Основными рабочими органами комбинированного укладчика являются цепной транспортер и дозирующий барабан. Мощность, необходимая для их привода, является одним из критериев [3], определяющих затраты на процесс укладки и общую эффективность использования укладчика.

Цель исследований - исследовать зависимости мощности от конструктивных и режим- 